\title{
Do people value bicycle sharing? A multilevel longitudinal analysis capturing the impact of bicycle sharing on residential sales in Montreal, Canada
}

\author{
Ahmed El-Geneidy, Dea van Lierop, \& Rania Wasfi \\ Paper accepted for publication in Transport Policy
}

April 2015

\begin{abstract}
Many studies have aimed to assess the impacts of major transportation investments, such as freeways expansions and light rail presence on property value. Yet, few studies have attempted to understand the impact of active transportation investments on housing prices. This study attempts to understand the relationship between a new bicycle sharing system and home sale prices in Montreal, Canada. Using multiple sales for units in multifamily housing that are reported in the Multiple Listings Service (MLS) of Montreal between 1996 and 2012 we develop step wise multilevel longitudinal hedonic regression models analyzing this relationship while controlling for various spatial and temporal factors that are known to impact home sales. Our results show that the presence of a bicycle sharing system in a neighborhood with 12 stations serving an 800 meter buffer is expected to increase the property value for units in multifamily housing by approximately 2.7 percent. Policy makers wishing to improve the local urban environment while benefiting from economic gains can work on increasing the availability of bicycle sharing systems as this will likely result in increasing property values, improved neighbourhood health, and a more vibrant urban environment.
\end{abstract}

For citation please use: El-Geneidy, A. van Lierop, D., \& Wasfi, R. (accepted). Do people value bicycle sharing? A multilevel longitudinal analysis capturing the impact of bicycle sharing on residential sales in Montreal, Canada. Transport Policy. 


\section{INTRODUCTION}

The choice for a household to locate in a particular type of housing unit in a given area is a complex decision that is influenced by both the structural elements of a building as well as by a property's spatial relationship to certain amenities. Access to different modes of transportation is considered to be an especially influential factor in determining housing location and setting land prices (Boyle \& Kiel, 2001; Levinson \& Krizek, 2007). Home location is influenced by both land use and transportation, which are unequivocally connected to an individual's quality of life (Geoghegan, Wainger, \& Bockstael, 1997).

The relationship between housing prices, and transportation costs and options were first explored in the land rent models proposed first by Alonso (1964) and later by von Thünen (1966). Assuming an urban area with a single market location, these authors built models to determine the trade-off costs influencing individuals' choices pertaining to home location and transportation choices. Since these early mono-centric models, the literature on residential choice theory has developed not only to include poly-centric analyses (Franklin \& Waddell, 2003), but also developments in understanding access to transportation systems (Armstrong \& Rodriguez, 2006; Cervero \& Duncan, 2002; Franklin \& Waddell, 2003; Palmquist, 1982). While many studies have assessed property value by including measurements of accessibility such as determining the value of road infrastructure and transit (Cervero \& Duncan, 2002; Dubé, Thériault, \& Des Rosiers, 2013; El-Geneidy \& Levinson, 2006; Franklin \& Waddell, 2003), few have attempted to understand the impact of active transportation facilitating infrastructure on housing prices (Krizek, 2007; Pivo \& Fisher, 2011). To our knowledge, no studies have attempted to understand the impacts of new bicycle sharing systems on home sales. Therefore, the present article attempts to understand this relationship and utilizes the hedonic modelling techniques derived from Lancaster (1966) and Rosen (1974) to analyze home sale prices and access to the bicycle share system in Montreal, Canada while controlling for various factors that are well known to impact home sales.

\section{LITERATURE REVIEW}

The existing literature that discusses the relationship between property values and active transportation is sparse and includes several contradictory findings. For example, Krizek (2007) attempts to understand the fiscal values associated with bicycle paths in Minneapolis-St. Paul, 
Minnesota. He found that bicycle facilities significantly reduced home values in suburban locations, and suggests that homebuyers may not consider bicycle paths as amenities. However, Krizek (2007) concludes his study by stating that further research is needed for urban planners, policy officials, and decision-makers to assess the true costs and benefits of bicycle facilities. Although not directly focusing on the relationship between bicycle facilities and property values, Lindsey, Man, Payton, and Dickson (2004) measure the effect of greenways on home sales price in Marion County, Indiana. The authors state that people using the greenway undertake activities such as cycling. In contrast to Krizek's (2007) study, these authors find that greenways generally have a positive or neutral effect on home sales prices.

Some studies analysed the walkability of a neighborhood and linked Walk Scores to property value. Walk Score is a tool that gives a score between 0 and 100 to an address based on an estimate of neighborhood walkability that is determined by measuring access to different facilities (Carr, Dunsiger, \& Marcus, 2010). For each address, the tool analyzes hundreds of walking routes to nearby amenity categories such as retail, recreation and leisure opportunities. Points are awarded based on the distance to amenities in each category. Amenities within a five minute walk ( 0.25 miles or $0.4 \mathrm{~km}$ ) are given maximum points. The Walk Score tool uses a decay function to attribute points to more distant amenities, but stops giving points for attractions beyond a 30-minute walk. It also measures pedestrian friendliness by analyzing variables such population density and block length. Data sources used by this tool include Google, Education.com, Open Street Map, Census and Localeze (WalkScore, 2014).

Pivo and Fisher (2011), were the first to analyze property values using Walk Score data and found that a ten percent increase in walkability increased property values up to nine percent (Pivo \& Fisher, 2011). A separate study by Rauterkus and Miller (2011) examined the relationship between land values and Walk Scores for a sample of properties in Jefferson County, Alabama. They found that higher Walk Scores positively influence property values, and used these findings to make policy recommendations that favoured mixed-use developments and sustainable communities. In another study, Walk Score was tested in terms of its capability to explain walking trips and was found to be a reliable source (Manaugh \& El-Geneidy, 2011).

The limited and recent literature that uses Walk Score data to analyse the relationship between property values and the walkability of neighbourhoods suggests that walkable neighbourhoods not only benefit the residents who own and/or reside in these areas, but that 
increases in property values also directly benefit municipalities due to higher property taxes (Pivo \& Fisher, 2011; Rauterkus \& Miller, 2011). These studies show that facilitating active transportation or the presence of a built environment that facilitates walking and cycling is expected to have a positive impact on land values.

Although to our knowledge there is no relevant literature on bicycle sharing and home sales, other literature aiming to understand the effects of bicycle sharing systems have been published since these cycling facilities have become increasingly popular in many cities in recent years (Bachand-Marleau, Lee, \& El-Geneidy, 2012; DeMaio, 2009). Even though these systems are gaining popularity all over the world, the instability of the financial market is causing a challenge for cities to keep their bicycle sharing facilities running. These financial struggles have resulted in a need for studies that are able to quantify some of the economic benefits to the society that bicycle sharing systems offer, in addition to their transport, health and environmental benefits (Bachand-Marleau, Larsen, \& El-Geneidy, 2011; Shaheen, S., \& Zhang., 2010). Based on data from 2010, bicycle sharing systems are present in over 125 cities on four continents, which translates into about 140,000 shared bicycles worldwide (Shaheen, Guzman, \& Zhang, 2010). Today these numbers have increased due to the high adoption of these systems. Yet, no study to date has attempted to quantify the benefit of this system on property values.

\section{DATA AND METHODOLOGY}

Based on the abovementioned literature, as well as Krizek's (2007) call for further research about the relationship between cycling infrastructure and home sales, the present study uses a hedonic regression analysis based on a sample of repeated housing sales in Montreal, Canada, to explore the factors influencing the sale prices in the region. Similarly to the aforementioned studies by Pivo and Fisher (2011) and Rauterkus and Miller (2011), this study includes Walk Score data to control for some neighborhood characteristics and local accessibility (Manaugh \& El-Geneidy, 2012). Other control variables are included in the model such as the structural and spatial attributes of properties, and the availability of transportation services.

Data from the Multiple Listings Service (MLS) of Montreal, Canada, is used to generate the hedonic model. In the period between 1996 and 2012 a total of 440,965 home sales are recorded in the system. These include sales of single family houses as well as housing units in multifamily housing. In many neighbourhoods in Montreal multifamily housing is dominant, and is composed 
of duplexes, triplexes, other row houses, apartment units, or condos. . Because hedonic analyses of repeat sales have been found to be more efficient and accurate than others (Bailey, Muth, \& Nourse, 1963), our analysis is limited to repeated sales only that took place during this time period with a maximum number of six sales and a minimum of two sales. Limiting the analysis to repeated sales allows us to better understand the changes in the property value overtime and control for the presence of the new bicycle sharing system which was introduced in to Montreal in the early spring of 2009. Due to the nature of the repeated sales, a longitudinal modeling technique is required that can account for the nature of the data. Such technique accounts for the notion that multiple observations in the data are coming from the same source. It is important to note that no other previous bicycle sharing systems every existed in the city. In other words, bicycle sharing in Montreal is only present during the years past 2009. The database obtained from the MLS includes information about home location, as well as the structural information of a property. Using a Geographic Information System (GIS), the address of each property was mapped to allow for further spatial analysis. Figure 1 demonstrates the study area in relation to the central business district (CBD), rail transit, and bicycle share stations. The study area included areas that experienced the addition of new bicycle sharing systems as well as control areas where bicycle sharing was not present during the entire study period. Also sales that took place before the presence of bicycle sharing system as well as others that took place after the introduction of the bicycle sharing system. Sales that were less than $\$ 70,000$, were removed from the data as they were likely to be unrepresentative of market value. In addition, properties with more than seven bedrooms or more than five bathrooms were removed, as well as sales worth more than one million dollars, as they were outliers and did not accurately represent the market. Finally, sales that took place in the same year were excluded as they were likely to be distress sales. Units that had a sales price in one time period lower than a previous sale that took place earlier were removed to account for sales that took place based on financial stress as well. Finally, units with zero bathrooms were excluded from the analysis. Since the majority of the areas where bicycle sharing is present in Montreal are dominated by multifamily housing our study will only concentrate on this type of housing. The data presented here, therefore, only accounts for residential properties in multifamily housing that were sold multiple times between the years 1996-2012. The data includes 5,037 units in multifamily housing transactions coming from 2,419 establishments. These include condos, 
apartments, studios, lofts, duplexes, triplexes, row houses and two or more stories units. These multifamily housing units are spatially distributed in 320 census tracts.

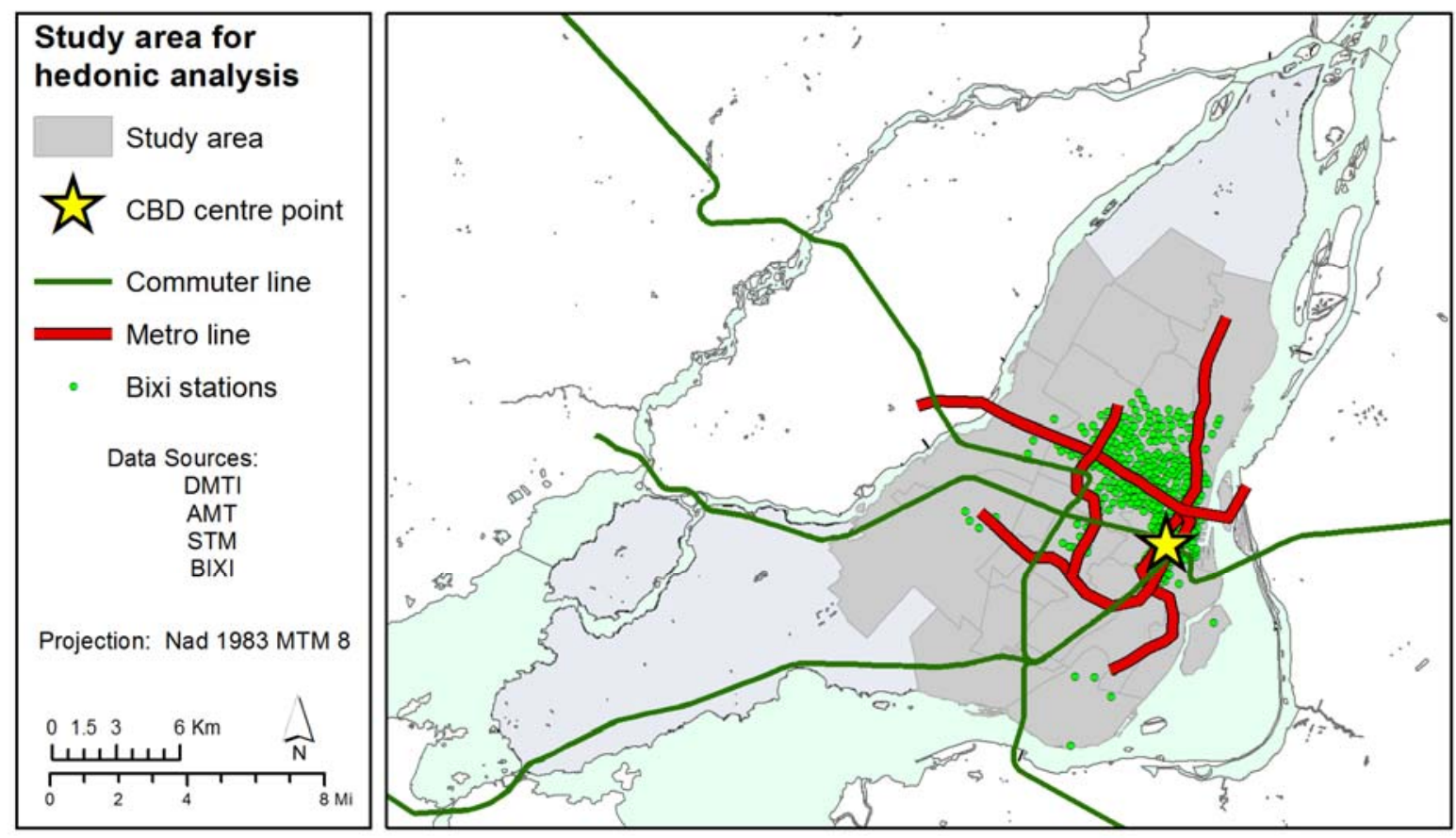

Figure 1: Study area for hedonic analysis

The dependent variable used in this study is the sale price of the property in Canadian dollars. Table 1 presents the variables used in the analysis, as well as summary statistics. The mean sales price of a property in the area of study is \$266,553.30 for units in a multifamily housing during the entire study period. The independent variables are categorized into structural, neighborhood, and transportation and spatial categories. All structural data comes from the MLS database. Included variables are the number of bedrooms (1.88 for units in multifamily housing), number of bathrooms above ground (1.19 for units in multifamily housing), livable area in square meters (98 $\mathrm{m}^{2}$ for units in multifamily housing), a dummy variable that equals to one if the unit includes a basement, a dummy variable if the unit has a water view or access to the waterfront, and a dummy variable if the unit has at least one indoor garage. The age of the buildings was calculated by subtracting the year the unit was constructed from the sale date of the property. The mean age was 27.87 years old for units in multifamily housing. These variables are included based 
on reviewing previous studies (Armstrong \& Rodriguez, 2006; El-Geneidy \& Levinson, 2006; John, 1996; Krizek, 2007).

Neighborhood and transportation and spatial variables included both accessibility and availability of service measures. Accessibility is generally referred to as the potential opportunity for activity and interaction (El-Geneidy \& Levinson, 2006; Handy \& Clifton, 2001; Hansen, 1959). A popular new way to measure the local pedestrian accessibility for a particular location is by using Walk Score (Manaugh \& El-Geneidy, 2012). As mentioned earlier in the paper, this score determines the walkability of a location and is an accessibility measure that awards points based on how many amenities an individual can access from a particular location. It is calculated using a simple gravity-based measure to weigh nearby locations higher than those more distant. Therefore, the higher the score is, the more amenities, shops, and entertainment located close to a given point, and the more walkable a neighbourhood is (Manaugh \& El-Geneidy, 2011; Walk Score, 2013). This variable also includes distance to neighbourhood facilities such as parks, schools, and police stations. To generate a Walk Score variable for this model, data was obtained from the Walk Score website, and linked to each household using a spatial join in GIS. Before the Walk Score data was included in the model, other neighbourhood characteristics such as land use and amenities were included as separate variables in the model. However, these variables were removed from the final model because the available Walk Score data is more comprehensive as a local accessibility measure (Manaugh \& El-Geneidy, 2012). This variable was also found to be highly correlated with distance to city center; the variable measuring the distance to city center was therefore omitted from the model. Regional accessibility was accounted for by including a gravity based measure of regional accessibility. This measure is derived based on 2006 census information regarding the number of jobs, using a distance decay discounting factor for the number of jobs based on data obtained from Montreal Origin-Destination survey from 2003, and travel times obtained from the Ministry of Transport of Quebec. ${ }^{1}$ This variable represents the discounted number of jobs available for people residing in the postal code at the regional level using an automobile as their mode of transportation. Although the Walk Score variable is useful in calculating the pedestrian accessibility of a given location and the gravity measure is a measure of

\footnotetext{
${ }^{1}$ For more information regarding gravity based measures of accessibility and their impacts on home values and how they substitute for distance to downtown measures in hedonics please refer to El-Geneidy and Levinson (2006). Also, for details about advantages or disadvantages of gravity-based measure of accessibility please refer to Geurs and van Wee (2004) and Handy and Niemeier (1997).
} 
regional accessibility, neither of these variables account for the availability of transit or access to the bicycle sharing network. Therefore, to account for these transport-related neighbourhood characteristics, other spatial attribute variables in the model measure the distance to the nearest metro station, commuter train station and on ramp leading to a freeway. Montreal's bicycle share system was first introduced in the spring of 2009. All sales that took place before 2010 were therefore assigned a bicycle sharing score of 0 , accounting for the fact that this bicycle share infrastructure would not have been able to influence property value before its pilot implementation in the spring of 2009. While transactions taking place after 2010 were assigned a value representing the number of bicycle sharing stations within an 800 meters buffer generated around the residential unit. When bicycle sharing is present around a multifamily housing unit, the average number of stations was 12.25 stations with a maximum number of 34 stations.

The model does not include distance to bicycle facilities such as paths, lanes, and boulevards, as the quality of bicycle facilities varies largely, and cyclists have not always been found to prefer bicycle specific facilities. For example, a recent study in Montreal found that many cyclists preferred using quiet residential streets than other bicycle facilities (Damant-Sirois, Grimsrud, \& El-Geneidy, 2014). To substitute for the bicycling facility variables we tested a variable derived from the percentage of bicycle trips in the region passing through the neighborhood. This variable was later dropped from the analysis due to its correlation with other important variables in the model such as Walk Score.

However, the model does include a spatial attribute variable that calculates the median income of each address in the database obtained from the census tract in which it is located. This variable was calculated using a spatial join in GIS, and according to the literature is considered to be one of the most important factors in determining residential values. For every housing unit sold, a unique identification number was generated based on the address to identify the several sales of the same unit. The data was then set as longitudinal data with the sale year as the time variable. 
Table 1: descriptive statistics

\begin{tabular}{|c|c|c|c|c|}
\hline Variable & Mean & St Dev. & Min & Max \\
\hline Sale Price (Canadian dollars) & $\$ 266,553.30$ & $\$ 119,603.30$ & $\$ 70,000.00$ & $\$ 995,000.0$ \\
\hline \multicolumn{5}{|l|}{ Structural variables } \\
\hline $\begin{array}{l}\text { Number of bedrooms above ground } \\
\text { (number) }\end{array}$ & 1.88 & 0.77 & 0.00 & 5.00 \\
\hline Number of bathrooms (number) & 1.19 & 0.41 & 1.00 & 4.00 \\
\hline Living area (meters) & 98.88 & 37.36 & 22.40 & 1187.00 \\
\hline Age at time of sale (years) & 27.87 & 32.54 & 0.00 & 189.00 \\
\hline $\begin{array}{l}\text { Age at time of sale Squared (years } \\
\text { square) }\end{array}$ & $1,835.39$ & $3,593.25$ & 0.00 & $35,721.00$ \\
\hline The unit includes a basement (yes or no) & 0.15 & 0.36 & 0.00 & 1.00 \\
\hline $\begin{array}{l}\text { The unit has a water view or access (yes } \\
\text { or no) }\end{array}$ & 0.10 & 0.30 & 0.00 & 1.00 \\
\hline $\begin{array}{l}\text { A garage is present for the unit (yes or } \\
\text { no) }\end{array}$ & 0.47 & 0.50 & 0.00 & 1.00 \\
\hline Transaction Year & $2,008.57$ & 2.41 & $1,996.00$ & $2,012.00$ \\
\hline
\end{tabular}

Neighborhood variables

Median household income in the census tract (in 1,000 Canadian dollars)

Walkscore for the postal code (0 to 100)

$\begin{array}{lccc}44.92 & 19.72 & 0.00 & 210.84 \\ 79.32 & 14.58 & 28.00 & 100.00\end{array}$

\section{Transportation and spatial variables}

Distance to the nearest Metro station (meters)

$\begin{array}{cccc}1,546.26 & 1612.19 & 0.00 & 9,951.70 \\ 4,989,559.00 & 12,600,000.00 & 0.00 & 99,000,000.00 \\ 3,795.57 & 2,666.88 & 0.00 & 13,783.65 \\ 55,415.89 & 22,188.73 & 0.00 & 110,003.90 \\ 1,818.55 & 1,230.46 & 0.00 & 4,663.34 \\ 4,820,917.00 & 5,256,948.00 & 0.00 & 21,700,000.00 \\ 3.20 & 7.19 & 0.00 & 34.00\end{array}$

Distance to the nearest Metro station square (meters)

Distance to the nearest commuter train station (meters)

Gravity Based Accessibility Measure to jobs (jobs)

Distance to the nearest freeway on-ramp (meters)

Distance to the nearest freeway on-ramp

Square (meters square)

Number of Bicycle sharing stations after 2009 (number) 


\begin{tabular}{lcccc}
\hline Variable & Mean & St Dev. & Min & Max \\
\hline Sale transaction took place during the & & & & \\
Bicycle sharing season (yes or no) & 0.66 & 0.47 & 0.00 & 1.00 \\
\hline $\begin{array}{l}\text { Number of observations } \\
\text { Number of homes sold }\end{array}$ & 5,037 & & & \\
\hline
\end{tabular}

The selection of the appropriate statistical technique was a challenge for this exercise due

to the large number of variables that changed over time and due to the number of variables that could cause a bias in the statistical model that we could not control for. Using multiple sales enabled us to model the data as longitudinal and control for many of the missing factors that we do not have data for such as housing quality or amenities as they were not present in the data obtained from the MLS. However, it is important to report that variations between the neighborhoods where the bicycle sharing system has been implemented in Montreal exist. For example, while some of the areas are known to be trendier than others and attract more young residents, others are known to be higher-end, or located nearer to the CBD. To account for this variation we used a multilevel modeling technique at the census tract level (Canadian census tract) allowing for variation within the neighborhood to be highlighted while still capturing the variation between neighborhoods. The Canadian census tracts are small geographic stable areas; they usually have a population of 2,500 to 8,000 and are located in large urban centers that must have an urban core population of 50,000 or more. Since each multifamily unit is expected to have a different value in its first sale, we used a random intercept model. This modeling technique helps in controlling for the variation between multifamily units and between neighborhoods. The final modeling technique is a longitudinal multilevel random intercept model. Using this technique allows us to handle clustering in the data. Ignoring the clustering generally leads to incorrect estimated standard errors (Rabe-Hesketh \& Skrondal, 2012). The multifamily-specific error component in this model represents the combined effects of omitted characteristics or unobserved heterogeneity at the multifamily unit level. Explanation of the model in more detail is present in the next section.

\section{RESULTS}

Table 2 (below) shows the results of the built-up longitudinal multilevel random intercept hedonic regression models. Comparing Log restricted-likelihood, the Akaike Information Criterion (AIC) and Bayesian Information Criterion (BIC) values it is clear that the complete model is the one with the best fit and each addition made in the built-up regression increased the descriptive powers of 
the model. It is also observed that the values, directions, and statistical significance of the coefficients are generally stable even with the additions made in every model. Model 4, the final model that included the bicycle sharing variables, is the most interesting with regard to policy. This model has the highest descriptive power and will therefore be discussed in detail in the following section. It is important to note that several variables were tested in the models including number of bus stops, number of metro stations and number of commuter train station within an 800 meters buffer generated using the residential unit as the center of the buffer. Also distance to downtown and distance to downtown squared. In addition, we tested percentage of bicycle trips passing through the neighborhood compared to all trips in the region. These variables were excluded from the model either due to the high level of correlation with other variables or because they did not show statistical significance in the model. Only statistically significant variables are left in the models as well as control variables that are important to include for discussion purposes.

In terms of structural attributes, the number of bedrooms above ground, the number of bathrooms, and the livable area has a statistically significant positive effect on the multifamily home sales and the values are comparable to previous research. For every bedroom located above ground the home sale is expected to increase by $\$ 21,008.45$ for units in a multifamily housing while keeping all variables at their mean values. In order to better understand the modeling technique we will expand the explanation of this variable and compare it across the models. In Model 1, the model with the least number of variables and least explanation power each bedroom adds \$20,660.21. This variable changes to be \$20,775.82 in Model 2 and \$21,234.40 in Model 3. The difference in the impact of a bedroom on the sale of a multifamily unit between the complete model (Model 4) and the short model (Model 1) is \$730, such value represents $0.2 \%$ in the value of an average multifamily unit. In other words, using the longitudinal multilevel random intercept technique in Model 1 combined the effects of omitted characteristics or unobserved heterogeneity at the multifamily unit level leading to more accurate estimation for the impact of the bedrooms in Model 1. Such small difference increases our trust in the final model (Model 4). In other words any unobserved heterogeneity or omitted characteristics are controlled for when using this modeling technique. We compared estimating Model 1 and Model 4 using a regular regression and we found the impact of a bedroom in Model 1 to $\$ 12,971.9$ and \$20,277.8 in Model 4. This difference represents $\$ 7,305$ (2\% of a mean value of a multifamily unit). 
In Model 4 the increase in the livable area by one meter square leads to an increase of \$469.39 per meter squared for units in a multifamily housing while keeping all variables at their mean values. The model also shows that every bathroom adds $\$ 68,368$ multifamily housing units. The higher value of the impact of bathroom in multifamily housing is due to the high costs associated with bathrooms in this type of unit. These increases in property value that are associated with the number of bedrooms, number of bathrooms and floor area of a property demonstrate that home buyers are willing to pay for more space, which is consistent with the previous literature.

In contrast, property values are negatively affected by age. For every additional year that a property exists, its value decreases by $\$ 585.06$ for units in multifamily housing while keeping all variables at their mean values. The variable age squared is included to more accurately model the effect of the age of the property, which may have a non-linear relationship with sale price. Because some of Montreal's most desirable neighbourhoods are also the oldest, it is possible that there are properties who are enjoying a price premium similar to what was found in Chen, Rufolo, and Dueker (1998). The square indicates that for units in multifamily housing at the age of 48 years old and above their prices will decline every year at a different rate compared to the previous years. The inclusion of a basement in the dwelling unit increases its value by \$22,016 in units in multifamily houses. It is important to note that the presence of a basement is not common in the multifamily housing in the region. Having a water view or access adds \$42,944 in units in multifamily houses. Finally having a garage adds $\$ 45,925$ in units in multifamily houses while keeping all variables at their mean values. For the transaction date variables, the omitted variable was the first year in the data which is 1996. Following the expected theory, the values of the units in multifamily housing during the first five years was not significantly different from the values in 1996. In the years following 2002, a statistically significant and positive difference is present between the units sold compared to those sold in 1996. Every year a housing unit gains approximately $5 \%$ in comparison to the mean value of a multiple-family unit.

The neighborhood attributes in the model show that properties located in areas that facilitate nearby walking are more desirable and residents are willing to pay more for a higher walkable neighborhood. For every unit of increase in a location's Walk Score increases property value by $\$ 438.12$ for units in multifamily houses while keeping all variables at their mean values. This finding is consistent with previous research conducted by Pivo and Fisher (2011) and Rauterkus and Miller (2011). The impact of being in an affluent neighborhood is also captured in 
the models. For every \$1,000 increase in the median household income of the neighborhood where the housing unit is located the value of the unit is expected to increase $\$ 1,303$ while keeping other variables constant at their mean values.

Regarding the transportation and spatial attributes, the distance to the nearest Metro station (subway station) was found to have a statistically significant and negative impact on sale values of units in multifamily housing. In other words, people are willing to pay $\$ 12.60$ more for every meter closer to a metro station. Yet the square term defines the distance where such impact ends. The square term shows a statistically significant and positive impact with the increase in the distance. As mentioned earlier the two coefficients have to be interpreted together in term of their impacts on home sales. These two variables together demonstrate that the impact of being near the metro adds to the value of each unit, but the direction and magnitude of this impact changes at approximately 632 meters. However, the distance between the residential unit and the nearest commuter train station has a statistically significant negative impact on sale values. For every meter away from the station the home price is expected to decline by $\$ 3.00$. The square term for this variable did not show statistical significance in our models. We also tested distance to bus stops as well as bus stop counts and we found them to be highly correlated to walk scores so they were excluded from the analysis. These results, however, are not unexpected as Chen et al. (1998) found that property prices generally increase as their distance to a light rail station decreases. The last transportation infrastructure related variable is distance to the nearest freeway on-ramp. It is found that as the distance from the freeway on-ramp increases, the value of the house increases with a statistically significant relationship. The square term included in the model is statistically significant and shows that this relation is up to 2,000 meters from the freeway on-ramp. This means that residents are willing to be away from freeways to avoid the associated noise and pollution, but value having access by being no further than approximately one kilometer away to freeways that lead to many opportunities in the region. These findings are theoretically not surprising, and could have been predicted by Alonso's bid-rent function which demonstrates that individuals are willing to trade-off space, time, and money in their decision to locate on a particular property in a certain location (Alonso, 1964; Levinson \& Krizek, 2007).

The last transportation and spatial attribute included in the model is a regional accessibility measure. In this model we used gravity based accessibility, meaning that the values represented in the model are the weighted number of jobs. This variable had a mean value of 55,000 weighted 
jobs measured at the Metropolitan region scale. For every weighted job the housing unit is expected to increase by $\$ 1.07$. This finding is also consistent with previous research (El-Geneidy \& Levinson, 2006), where accessibility used to show a positive impact on home sale values.

The results of our main policy variable are that for every bicycle sharing station located within an 800 meter buffer around the residential property the property value is expected to increase by $\$ 709$ for units in multifamily houses while keeping other variables constant at their mean values. The mean number of stations in areas where bicycle sharing is present in Montreal was 12.26 stations around multifamily housing units. The magnitude that these variables add to the sale price is statistically significant and will be discussed further in the discussion and conclusion sections. The transactions that took place during bicycle sharing season did not show to be different from the ones that took place when the bicycle sharing system was not present in the neighborhood.

\section{Table 2: Multilevel longitudinal hedonic models}

Model 1

Structural variables
Number of bedrooms above ground
(number)
Number of bathrooms (number)
Living area (meters)
Age at time of sale (years)
Age at time of sale Squared (years
square)
The unit includes a basement (yes or no)
The unit has a water view or access (yes
or no)
A garage is present for the unit (yes or no)
Transaction Year
1997
1998
1999
2000
2001
2002
2003
2004
2005
2006

Model 2

Model 3

Model 4

\begin{tabular}{|c|c|c|c|}
\hline $20660.21 * * *$ & $20775.82^{* * *}$ & $21234.40^{* * *}$ & $21008.45^{* * *}$ \\
\hline $67904.65 * * *$ & $68162.38 * * *$ & $68267.51^{* * * *}$ & $68368.83 * * *$ \\
\hline $465.31 * * *$ & $467.46^{* * *}$ & $470.12 * * *$ & 469.39*** \\
\hline$-540.53 * * *$ & $-542.31 * * *$ & $-621.24 * * *$ & $-585.06 * * *$ \\
\hline $6.3166^{* * *}$ & $6.28 * * *$ & $6.60 * * *$ & $6.17 * * *$ \\
\hline $22102.12 * * *$ & $20706.53 * * *$ & $21824.87 * * *$ & $22016.47 * * *$ \\
\hline $40820.42 * * *$ & $44347.08 * * *$ & 42813.71*** & $42944.09 * * *$ \\
\hline $47483.99 * * *$ & $45417.93 * * *$ & $45821.93 * * *$ & $45925.63 * * *$ \\
\hline-9846.70 & -11056.45 & -9130.45 & -6952.34 \\
\hline 10514.28 & 9602.62 & 10547.92 & 10913.75 \\
\hline-11000.02 & -11609.75 & -10303.02 & -10080.86 \\
\hline 10384.18 & 9435.94 & 11003.27 & 12065.46 \\
\hline 36366.08 & 35594.99 & 37440.65 & 38249.01 \\
\hline $63177.66^{* *}$ & $62035.42^{* *}$ & $63672.43^{* *}$ & $64888.66^{* *}$ \\
\hline $81424.11^{* * *}$ & $80320.04 * * *$ & $82612.84 * * *$ & $83819.71^{* * *}$ \\
\hline $114751.69 * * *$ & $113812.13 * * *$ & $115538.55^{* * *}$ & $115707.38 * * *$ \\
\hline $110937.84^{* * *}$ & $109534.13^{* * *}$ & $111633.10 * * *$ & $113026.76^{* * *}$ \\
\hline $120643.32 * * *$ & $119297.40 * * *$ & $121454.94 * * *$ & $122698.26 * * *$ \\
\hline
\end{tabular}




\begin{tabular}{|c|c|c|c|c|}
\hline & Model 1 & Model 2 & Model 3 & Model 4 \\
\hline 2007 & $133955.18^{* * *}$ & $132729.38 * * *$ & $135048.40^{* * *}$ & $136342.24 * * *$ \\
\hline 2008 & $149763.36 * * *$ & $148437.55^{* * *}$ & $150833.32 * * *$ & $151957.87 * * *$ \\
\hline 2009 & $160460.41^{* * *}$ & $159198.10^{* * *}$ & $161433.01 * * *$ & $162758.25^{* * *}$ \\
\hline 2010 & $184162.83^{* * *}$ & $182892.23^{* * *}$ & $185549.74^{* * *}$ & $180987.47^{* * *}$ \\
\hline 2011 & $202955.55^{* * *}$ & $201731.28 * * *$ & $204284.54^{* * *}$ & $199505.39 * * *$ \\
\hline 2012 & $220312.19 * * *$ & $219160.84 * * *$ & $221661.70^{* * *}$ & $217072.60 * * *$ \\
\hline $\begin{array}{l}\text { Neighborhood variables } \\
\text { Median household income in the census } \\
\text { tract (in 1,000 Canadian dollars) }\end{array}$ & & $1350.05 * * *$ & $1289.38 * * *$ & $1303.78 * * *$ \\
\hline Walkscore for the postal code ( 0 to 100 ) & & $1309.51^{* * *}$ & $477.84^{*}$ & $438.12 *$ \\
\hline $\begin{array}{l}\text { Transportation and spatial variables } \\
\text { Distance to the nearest Metro station } \\
\text { (meters) }\end{array}$ & & & $-13.28 * *$ & $-12.62 * *$ \\
\hline $\begin{array}{l}\text { Distance to the nearest commuter train } \\
\text { station (meters) }\end{array}$ & & & $-3.41 * * *$ & $-3.38 * * *$ \\
\hline $\begin{array}{l}\text { Gravity Based Accessibility Measure to } \\
\text { jobs (jobs) }\end{array}$ & & & $1.11 * * *$ & $1.07 * * *$ \\
\hline $\begin{array}{l}\text { Distance to the nearest freeway on-ramp } \\
\text { (meters) } \\
\text { Distance to the nearest freeway on-ramp }\end{array}$ & & & $41.40 * * *$ & $40.02 * * *$ \\
\hline $\begin{array}{l}\text { Square (meters square) } \\
\text { Number of Bicycle sharing stations after }\end{array}$ & & & $-0.01 * * *$ & $-0.01 * * *$ \\
\hline 2009 (number) & & & & $709.84 * * *$ \\
\hline $\begin{array}{l}\text { Sale transaction took place during the } \\
\text { Bicycle sharing season (yes or no) }\end{array}$ & & & & 427.25 \\
\hline Constant & $-91794.85 * * *$ & $-250623.95 * * *$ & $-264866.60 * * *$ & $-260029.93 * * *$ \\
\hline Log restricted-likelihood & -61677.98 & -61608.02 & -61544.61 & -61509.34 \\
\hline AIC & 123412.00 & 123276.00 & 123161.20 & 123094.70 \\
\hline BIC & 123594.70 & 123471.80 & 123396.10 & 123342.60 \\
\hline lns1_1_1_cons & $10.79 * * *$ & $10.48 * * *$ & $10.32 * * *$ & $10.30 * * *$ \\
\hline lns2_1_1_cons & $10.95^{* * *}$ & $10.95^{* * *}$ & $10.93 * * *$ & $10.93 * * *$ \\
\hline lnsig_e_cons & $10.31^{* * *}$ & $10.31^{* * *}$ & $10.31^{* * *}$ & $10.31^{* * *}$ \\
\hline Total observations & 5037 & & & \\
\hline Individual units with multiple sales & 2419 & & & \\
\hline Number of Neighborhoods & 320 & & & \\
\hline
\end{tabular}

We used a multilevel longitudinal random intercept model in our analysis because the data shows a variation in the intercept where every house price starts at different point. Also to allow us to 
control for any omitted characteristics or unobserved heterogeneity. The LRT test showed that using a longitudinal random intercept model would be more appropriate than using a random effect regression model. Also we tested for the appropriateness of using multilevel technique, where multifamily houses where nested inside different neighbourhoods (proxied by the Canadian census tract) and found it to be statistically significant at the census tract level showing even much better model fits. Minor differences were noticed between the model coefficients in the structural and transportation variables when comparing the longitudinal only to the longitudinal multilevel model. Yet major differences were noticed in the magnitude of the coefficients associated with neighborhood level variables especially the Walk Score effect, which showed a more realistic impact on the home sales in the multilevel longitudinal models. The comparisons between the model fits are presented in Table 3. Also we tested the random effect regressions and they showed R-square of 0.708 for the units in multifamily houses.

Table 3: Model fitting comparisons

\begin{tabular}{ccccc}
\hline & & Log restricted-likelihood & AIC & BIC \\
\hline \multirow{4}{*}{ Longitudinal Models } & Model 1 & -62316.5 & 124686.9 & 124863.2 \\
& Model 2 & -62014.6 & 124087.2 & 124276.6 \\
& Model 3 & -61950.5 & 123970.9 & 124199.5 \\
& Model 4 & -61907.3 & 123888.7 & 124130.3 \\
\hline \multirow{2}{*}{ Multilevel } & Model 1 & -61678.0 & 123412.0 & 123594.7 \\
Longitudinal Random & Model 2 & -61608.0 & 123276.0 & 123471.8 \\
Intercept Models & Model 3 & -61544.6 & 123161.2 & 123396.1 \\
& Model 4 & -61509.3 & 123094.7 & 123342.6 \\
\hline
\end{tabular}

Table 4 shows the random effects parameters for model 4. The Intra-class correlation coefficient (rho) for the model suggests that approximately $18.1 \%$ of the variability of home prices is due to between neighbourhood variation, and $81.7 \%$ of the variability is due to between multifamily houses variability. The estimated $95 \%$ of the random coefficient of the home prices varied between approximately \$25,907 and \$34,587 at the neighbourhood level (census tract level) and between approximately $\$ 53,880$ and $\$ 58,216$ at the individual multifamily unit level.

Table 4: Random-effects Parameters of Model 4

\begin{tabular}{lllll}
\hline Random-effects Parameters & Estimate & Std. Err. & [95\% Conf. & Interval] \\
\hline $\begin{array}{c}\text { Census tract: Identity } \\
\text { sd(_cons) }\end{array}$ & 29934.68 & 2206.7 & 25907.56 & 34587.79
\end{tabular}


Individual unit: Identity

\begin{tabular}{cllll} 
sd(_cons) & 56006.18 & 1105.893 & 53880.08 & 58216.18 \\
sd(Residual) & 30044.78 & 460.2047 & 29156.2 & 30960.44 \\
\hline
\end{tabular}

In order to test further for causality of any omitted variable we assessed the results of a longitudinal multilevel fixed effect model. Such a model allows a complete control for omitted variables while excluding any variables that did not change over time. The impact of a bicycle sharing station was $\$ 698$ with a confidence interval of 496.6 - 899.5. This shows a difference of $\$ 10$ per station from our reported model, such small value can be related to the error term in the modeling techniques. Also it is important to note that the observed value in our model (Model 4) falls within the confidence interval of the fixed effect model. We preferred to report the longitudinal multilevel random intercept model since the coefficients reported are easier to understand by the reader and coefficients of all non-changing variables are reported.

\section{CONCLUSION}

Our model demonstrates that home sales prices in Montreal increase in locations that have better availability of bicycle share stations. Increasing the coverage of a bicycle sharing system will not only benefit the residents locating in these areas, but also act as an opportunity for municipalities to profit from higher property taxes. The average multifamily unit has access to approximately 12.2 stations, with the model demonstrating that each additional station adds $\$ 709$ to the value of the unit being sold in the period after the implementation of the bicycle sharing system in Montreal. This means an average \$8,649.8 addition for every unit in the area where bicycle sharing is present. This represents around $2.7 \%$ increase in the mean sale value of housing units in multifamily residential properties that were sold after 2010 (\$322,850). This amount represents more than half the increase in a multifamily unit in one year as the price generally increased by $4.8 \%$ in Montreal during the same period of time after 2009.

Like many changes in urban form, increasing the availability of bicycle share stations will have both proximal and non-proximal economic benefits. The immediate, or proximal, economic benefits stem from increases in municipal property taxes. However, it must be acknowledged that increasing the coverage of a bicycle sharing system or the number of station in an area will come at a cost. Cities that are considering the implementation or expansion of bicycle share systems must recognize that although seed capital can be high, increases in property taxes near bicycle 
sharing facilities might out weight the initial costs. This study has shown that bicycle sharing facilities are able to positively influence sales prices within a short timeframe, especially at the time when bicycle sharing systems are suffering from financial problems regarding their operating costs.

The present study used repeated sales only and used a multilevel longitudinal random intercept modeling technique to capture the impact of bicycle sharing system on sales of units in multifamily housing. It also included data from other areas in the region where bicycle sharing was not present to control for the general trends in the study area. In addition, some of the transactions that took place in the bicycle sharing area started and ended before the introduction of the bicycle sharing program in the region. The multilevel technique allowed us to control for any unobserved impacts on housing values at the neighborhood level such as cultures which we could not control for through a regular variable. As it was shown earlier through observing the stability of the models using this technique allowed us to control for many of the variations that can be found between units and not accounted for due to the absence of certain variables such as upgrades in a unit or higher quality of finishing. Such an approach is generally better than using a cross sectional data that shows only one transaction per unit. Also, using the multilevel approach enabled us to control for the within variation of a neighborhood and separate it from the between variation of neighborhood which was present due to the nature of the sites where bicycle sharing has been implemented in Montreal.

Although this analysis bases the choice of independent variables on previous studies, both additional spatial and structural attributes could be included in the model to develop a richer understanding of sales prices in Montreal. For example, the type of heating was not included in the model due to the inconsistency in the MLS data. Due to the nature of the location of the bicycle sharing system in Montreal the sample of single family houses in our dataset was limited. Yet, it is recommended to conduct similar studies in cities and regions where bicycle sharing is available near single family houses and covers a larger area to capture the impact of such system on single family houses. Another limitation is that we did not have access to commercial sales which could also capture the impacts of bicycle sharing systems and determine how they might benefit a region. However, even though additional variables could be included in future research, the present model does make clear that a significant relationship exists between home sale prices and availability of bicycle share stations in a neighbourhood. Policy makers wishing to increase the economic benefits 
of the municipal government and improve local urban environments can increase the availability of a bicycle share system as this will likely result in increased property sale prices, improved neighbourhood health, and a more vibrant urban environment.

\section{ACKNOWLEDGMENT}

The authors would like to thank Prof. James Strathman, of Portland State University for his insights on the modeling outputs as well as the three anonymous reviewers for their helpful feedback. Thanks to Mr. Paul Cardinal from Fédération des chambres immobilières du Québec for sharing the sales data to be used in research purpose. This research was funded by the Natural Sciences and Engineering Research Council of Canada.

\section{REFERENCES}

Alonso, W. (1964). Location and land use. Toward a general theory of land rent. Location and land use. Toward a general theory of land rent.

Armstrong, R., \& Rodriguez, D. (2006). An evaluation of the accessibility benefits of commuter rail in eastern Massachusetts using spatial hedonic price functions. Transportation, 33(1), 21-43.

Bachand-Marleau, J., Larsen, J., \& El-Geneidy, A. (2011). The much anticipated marriage of cycling and transit: But how will it work? . Transportation Research Record(2247), 109-117.

Bachand-Marleau, J., Lee, B., \& El-Geneidy, A. (2012). Towards a better understanding of the factors influencing the likelihood of using shared bicycle systems and frequency of use. Transportation Research Record(2314), 66-71.

Bailey, M., Muth, R., \& Nourse, H. (1963). A regression method for real estate price index construction. Journal of the American Statistical Association, 58(304), 933-942.

Boyle, M., \& Kiel, K. (2001). A survey of house price hedonic studies of the impact of environmental externalities. Journal of Real Estate Literature, 9(2), 117-144.

Carr, L. J., Dunsiger, S. I., \& Marcus, B. H. (2010). Walk score ${ }^{\mathrm{TM}}$ as a global estimate of neighborhood walkability. American journal of preventive medicine, 39(5), 460-463.

Cervero, R., \& Duncan, M. (2002). Benefits of proximity to rail on housing markets: Experiences in Santa Clara County. Journal of Public Transportation, 5(1).

Chen, H., Rufolo, A., \& Dueker, K. (1998). Measuring the impact of light rail systems on single-family home values: A hedonic approach with geographic information system application. Transportation Research Record, 1617(1), 38-43.

Damant-Sirois, G., Grimsrud, M., \& El-Geneidy, A. (2014). What's your type: A multidimensional cyclist typology. Paper presented at the 93rd Annual Meeting of the Transportation Research Board, Washington, D.C., USA.

DeMaio, P. (2009). Bike-sharing: History, impacts, models of provision, and future. . Journal of Public Transportation, 12(4), 41-56. 
Dubé, J., Thériault, M., \& Des Rosiers, F. (2013). Commuter rail accessibility and house values: The case of the Montreal South Shore, Canada, 1992-2009. Transportation Research Part A: Policy and Practice, 54, 49-66.

El-Geneidy, A., \& Levinson, D. (2006). Access to destinations: Development of accessibility measures. Minneapolis, MN.

Franklin, J., \& Waddell, P. (2003). A hedonic regression of home prices in King County, Washington, using activity-specific accessibility measures. Paper presented at the Proceedings of the Transportation Research Board 82nd Annual Meeting, Washington, DC.

Geoghegan, J., Wainger, L., \& Bockstael, N. (1997). Spatial landscape indices in a hedonic framework: An ecological economics analysis using GIS. Ecological Economics, 23(3), 251-264.

Geurs, K., \& van Wee, B. (2004). Accessibility evaluation of land-use and transport strategies: Review and research direction. Journal of Transport Geography, 12(2), 127-140.

Handy, S., \& Clifton, K. (2001). Evaluating neighborhood accessibility: Possibilities and practicalities. Journal of Transportation and Statistics, 4(2/3), 67-78.

Handy, S., \& Niemeier, D. (1997). Measuring accessibility: An exploration of issues and alternatives. Environment and Planning A, 29, 1175-1194.

Hansen, W. (1959). How accessibility shapes land use. Journal of the American Institute of Planners, 25(2), 73-76.

John, B. (1996). Mass transportation, apartment rent and property values. Journal of Real Estate Research, 12(1), 1-8.

Krizek, K. (2007). Two approaches to valuing some of bicycle facilities' presumed benefits. Journal of the American Planning Association, 72(3), 309-320.

Lancaster, K. (1966). A new approach to consumer theory. The Journal of Political Economy, 74(2), 132157.

Levinson, D., \& Krizek, K. (2007). Planning for place and plexus: Metropolitan land use and transport: Routledge.

Lindsey, G., Man, J., Payton, S., \& Dickson, K. (2004). Property values, recreation values, and urban greenways. Journal of Park and Recreation Administration, 22(3), 69-90.

Manaugh, K., \& El-Geneidy, A. (2011). Validating walkability indices: How do different households respond to the walkability of their neighborhood? Transportation Research Part D: Transport and Environment, 16(4), 309-315.

Manaugh, K., \& El-Geneidy, A. (2012). What makes travel "local": Defining and understanding local travel behavior. The Journal of Transport and Land Use, 5(3), 15-27.

Palmquist, R. (1982). Impact of highway improvements on property values in Washington state. Transportation Research Record(887).

Pivo, G., \& Fisher, J. (2011). The walkability premium in commercial real estate investments. Real Estate Economics, 39(2), 185-219.

Rabe-Hesketh, S., \& Skrondal, A. (2012). Mutlilevel and longitudinal modeling using stata: Volume I: Continuous responses (Third Edition ed.). College Station, Texas, USA: Stata Press.

Rauterkus, S., \& Miller, N. (2011). Residential land values and walkability. The Journal of Sustainable Real Estate, 3(1), 23-43.

Rosen, S. (1974). Hedonic prices and implicit markets: Product differentiation in pure competition. The Journal of Political Economy, 82(1), 34-55.

Shaheen, S., Guzman, S., \& Zhang, H. (2010). Bikesharing in Europe, the Americas, and Asia: past, present and future. Transportation Research Record(2143), 159-167.

Shaheen, S., S., G., \& Zhang., H. (2010). Bikesharing in Europe, the Americas, and Asia: Past, present and future. Transportation Research Record(2143), 159-167. 
von Thunen, J. H. (1966). Isolated State; an English edition of Der Isolierte Staat. Oxford: Pergamon Press.

Walk Score. (2013). http://www.walkscore.com/. 2013

WalkScore. (2014). Find your neighborhood walk score. Retrieved May, 2014, from http://www.walkscore.com 